\begin{tabular}{ccc}
\hline & International Journal of Engineering \& Technology, $7(3.35)(2018) 30-31$ \\
SPC & International Journal of Engineering \& Technology \\
Website $w$ ww.sciencepubco.com/index.php/IJET & Research paper \\
\hline
\end{tabular}

\title{
Slope Stability Analysis for Proposed Footing Construction Seated on Sloppy Ground
}

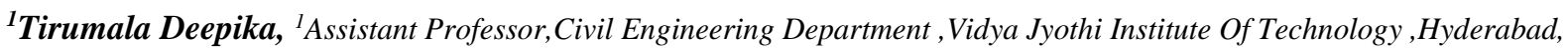 \\ *Email: tirumaladeepika733@gmail.com
}

\begin{abstract}
Slope failures are one of the common phenomena in the Geotechnical failures. Thus it is needed to arrest the failure through proper mechanism. Considering this as a scope the present study is oriented to address the analysis of sloppy site where the proposed building foundation to be constructed with different slopes as a natural construction site. The stability is checked and the anchors are used to improve the stability aspect of slope. The study found that the homogeneous soil slope is improved its safety under the usage of anchors.
\end{abstract}

Keywords: slope stability, anchors, factor of safety, forces bearing capacity

\section{Introduction}

Day to day India is a developing country, as there is an increase in population civil engineering construction projects are mandatory to build on sloppy ground due to insufficient land as per the standards. Anchors can be used as the reinforcement to the soil to polish up the stability of slope, bearing capacity of foundation is very important factor to be considered. Analysis of high buildings in the hilly areas is different compare to the buildings on the levelled ground because the columns will be places at different positions on the slope. The building loads are transferred to the slope which causes slope failure.

\section{Literature review}

A.P.S Selvadurai and C.T Gnanendran They have studied on performance of a model footing on a reinforced sloped fill by using reinforced concrete test tank having dimensions of $1500 \mathrm{~mm}$ in length, $880 \mathrm{~mm}$ in width and $1200 \mathrm{~mm}$ in depth. First they have been placed the compacted soil secondary a compacted soil with geogrid, then they compacted soil above the level og geogrid reinforcement layer. Lastly they have been placed a strip foundation and slope formed by excavation of compacted soil at $1 \mathrm{~V}: 2 \mathrm{Hand}$ observed the deformation and settlement behavior of the footing which is located at the crest of the slope fill increased by placing a geogrid.

Hamed niroumand and k.a.kassim, r. Nasir. The present paper is an effort to quantify the strength of the soil by using different types of soil anchors such as helical, grouted, plate and pile anchors in a type of cohessionless soils. It has been concluded that helical system is a good type because it is not needed any grout, by using anchors it can be increase the uplift response, speed of analysis in the upcoming projects.

Rajesh prasad shukla. This paper represents the study of foundations constructed near or on the slopes and taken different bearing capacity factor with respect to slope analysis.

Jao.et.al (2008). This paper studies about the strip footing on sloping ground which is loaded eccentrically and they observed the different parameters such as pressure and settlement are not affected but bearing capacity of footings were affected by eccentricity loaded.

Alamshahi,Sand Hataf. This paper conducted a series of experiments on finite element method with and without model test and also included reinforcement in the soil and compared the values. Therefore it has been concluded that by inserting the reinforcement there is an increase in bearing capacity.

J. Kumar and Chakra Borty D. This paper evaluated the bearing capacity of smooth and rigid using finite element. The difference of bearing capacity was given with variation in slope angle and friction angle.

Saran et al.(1989). The replacements of equivalent surcharge with footing load. It has been assumed that failure of time and sloping strength of one side is mobilized and on other side only little percentage of strength is mobilized by using a factor of mobilization.

Nicoleta- Mariailies ${ }^{a}$, Ioana-Madalina Moldavan ${ }^{a}$ SilivanVlentin Moldavan ${ }^{\mathrm{a}}$. This paper has studied how an underground structure is reflected by slope stability. In this paper they have selected various stratification of soil and introduced slope characteristics in the GEO5 software and for accurate slopes with different grades were selected and concluded that after conducting many simulations with software by the method of fellunius method depending upon variations had different effects.

R.K.Sharma, Vishal Kumar, Nandika Sharma, Ajender Rathore studied the slope stability analysis to arrest the slope failures. In this study the factor of safety has been determined using Geo5 software and also internal friction, cohesion and unit weight of soil.

\section{Methodology}

By using the geotechnical software geo5 slope stability module (13), by considering EN 1997-1(EC 7-1, DA2) standard the slope stability has been analysed. The nation annex of Eurocode 7 recommends for the slope stability analysis to use the safety factors corresponding to the design approach 1 combination 2 (DA-2) and to the design approach 3(DA3). Considering the values of the safety factors, for the analysis (DA-2) and (DA3) are identical, therefore the calculus is performed for (DA-2).The numerical finite element model of the slope with following 
engineering parameters is developed for analysis. The slope considered in the stability analysis has $100 \mathrm{~m}$ length for this analysis two different inclinations has been considered i.e. $30^{\circ}$ and 45.Stability analysis is performed with Geo5 software and the parameters of the soil is taken as $\gamma=18 \mathrm{kN} / \mathrm{m}^{\wedge} 3, \varphi=30^{\circ}, \gamma \mathrm{sat}=20$ $\mathrm{KN} / \mathrm{m}^{\wedge} 3$, Depth of ground water table $=3.53 \mathrm{~m}$ (from level ground), Anchor for stabilizing soil slope $=300 \mathrm{KN}$. The analysis of homogeneous finite slope is carried out for static loading condition. The loads on a foundation are considered as a building load for which the foundation is subjected.

Table.1: Ground properties

\begin{tabular}{|c|c|c|}
\hline S.No & Description & Dimensions \\
\hline 1 & Length & $100 \mathrm{~m}$ \\
\hline 2 & Inclination & $30^{\circ}$ And $45^{\circ}$ \\
\hline 3 & Water Table Depth & $\begin{array}{c}3.53 \mathrm{~m} \text { (From Ground } \\
\text { Level) }\end{array}$ \\
\hline
\end{tabular}

Table.2: Forces acting on the ground

\begin{tabular}{|c|c|c|c|}
\hline & $\mathbf{3 0}^{\circ}$ & $\mathbf{4 5}$ & $\begin{array}{c}\text { After } \\
\text { Anchoring }\end{array}$ \\
\hline $\begin{array}{c}\text { Sum of Active forces } \\
(\mathrm{KN})\end{array}$ & 576.51 & 303.30 & 256 \\
\hline $\begin{array}{c}\text { Sum of passive forces } \\
(\mathrm{KN})\end{array}$ & 964.50 & 1569.30 & 347 \\
\hline $\begin{array}{c}\text { Sliding Moment (KN- } \\
\mathrm{m})\end{array}$ & 4730.66 & 6553.02 & 2539 \\
\hline $\begin{array}{c}\text { Resisting Moment (KN- } \\
\mathrm{m})\end{array}$ & 7156.59 & 19933.8 & 12560 \\
\hline Factor of safety (1.5) & 1.51 & 3.05 & 2 \\
\hline
\end{tabular}

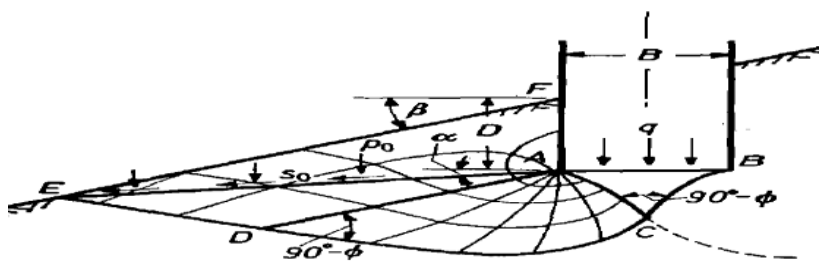

Fig. 1. Failure plane, Meyerhofs Theory for shallow foundation near slope

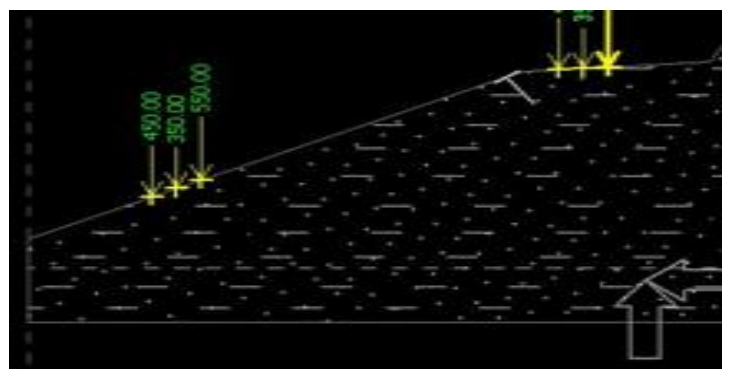

Fig. 2. $30^{\circ}$ inclination wiyh ground

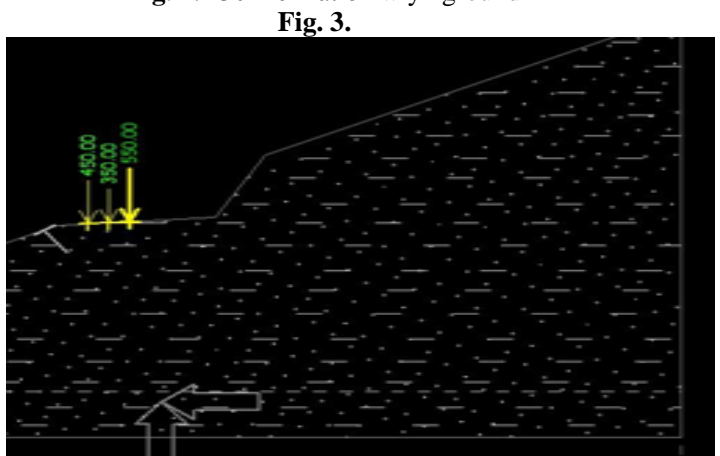

Fig. 4. $45^{\circ}$ inclination with ground

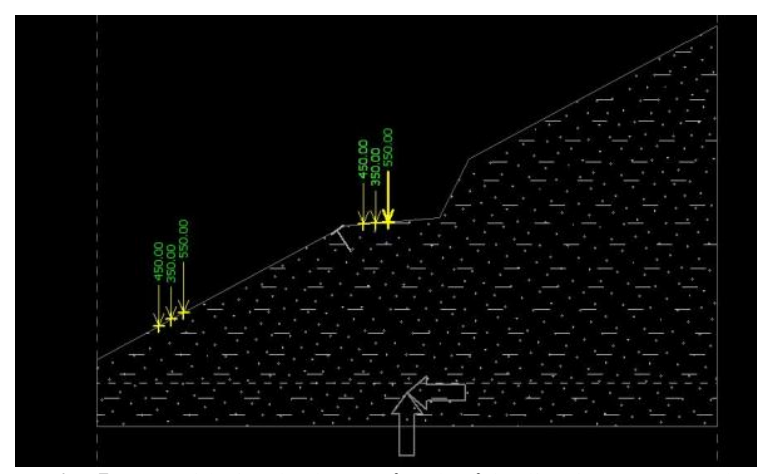

Fig. 5. Considering both at $35^{\circ}$ and $45^{\circ}$ inclination on ground

\section{Results and discussions}

The natural slope is analyzed against static load in two different zones for $30^{\circ}$ and $45^{\circ}$ inclination. For zone $30^{\circ}$ inclination the active forces is $576.51 \mathrm{kN}$ and passive force is $964.50 \mathrm{kN}$ where as the sliding moment is $4730.66 \mathrm{kNm}$ and Factor of safety is 1.5. By comparing the values of the two zones $30^{\circ}$ and $45^{\circ}$ shows From Table 2 it is found that forces are more active for $30^{\circ}$ inclination slope and hence required to use the anchor with suitable anchoring. After applying the anchors the active forces reduces and brings the factors of safety into considerable level. It also been observed that the slope with inclination $45^{\circ}$ is safer than $30^{\circ}$ inclination.

\section{Conclusion}

1. The bearing capacity of the soil is one of the governing parameter which decides the slope stability in static condition

2. The different in inclinations governs the slope failures.

3. By insertion of anchors improves the slope stability.

4. Geo5 is found to be one of the user-friendly tool to model the slope.

\section{References}

[1] Castelli F. and Lentini V. (2012) Evaluation of the bearing capacity of footings on slopes. International Journal of Physical Modelling in Geotechnics, Vol. 12, No. 3, pp $112-118$.

[2] Kumar, J. and Ghosh, P., (2006) Seismic bearing capacity for embedded footings on sloping ground". Géotechnique, Vol. 56 No. 2, , pp $133-140$

[3] Meyerhof, G. G. (1957) The Ultimate Bearing Capacity of Foundation on Slopes, Proceedings of the 4th International Conference on Soil Mechanics and Foundation Engineering, Vol.3, pp. 384-386

[4] Chen Y.C (1996). Bearing capacity of strip footings near sloping ground during earthquakes, Proc. of 11 World Conference on Earthquake Engineering.

[5] Braja M Das (1990). Earth Anchors. Elsevier.

[6] Michalowski, R.L. (1989) Three dimensional analysis of locally loaded slope. Geotechnique, Vol. 39, No. 1, 27-38. Sarma S.K. And. 